\title{
Job Satisfaction of the Bulgarian Primary Care Physicians
}

\author{
Tsvetelina Valentinova* \\ Department of General Practice, Medical University of Pleven, Bulgaria
}

*Corresponding author: Tsvetelina Valentinova, Department of General Practice, Forensic Medicine and Deontology, Faculty of Public Health, Medical University of Pleven1, St. Kliment Ohridski Str. 5800 Pleven, Bulgaria

submission: July 20, 2018; Published: September 17, 2018

\begin{abstract}
The job satisfaction of physicians is an important factor that influences their motivation for work and the quality of the provided health services. The aim of the study is to evaluate the job satisfaction of General Practitioners in Bulgaria and to explore some of the factors which influence this satisfaction.

Methods: A cross-sectional survey was conducted using a self-administered questionnaire in the period January-June 2017. The data were collected from 136 General Practitioners working in 136 primary care practices from different regions across the country. The job satisfaction was measured with the 10-item Warr-Cook-Wall job satisfaction questionnaire using the 7-step Likert rating scale.
\end{abstract}

Results: The Participants generally reported very high weekly workload, low satisfaction with the recognition of work, with the income and the hours of work. The respondents reported the high level of responsibility in the work, of the opportunity to use the abilities, and the relationships with colleagues.

Keywords: General practice; Job satisfaction; Physicians

\section{Introduction}

The organizational reform of the health care system in Bulgaria was started in 2000. As a result, the primary health care in the country was organized in a new way -based on individual and group practices of general medicine. The new conditions and organization of work, the new requirements and the new organization of training have become a challenge for general practitioners working in these practices. The work in difficult conditions can become a factor that

seriously reduces job satisfaction as well as motivation for work. In Bulgaria for recent years there is an unfavorable tendency to reduce the number of GPs working in the country, which is probably related to their satisfaction with the working conditions (Figure 1). The job satisfaction of the primary care physician is an important factor for quality of health, because the primary care level is responsible for providing medical care to a greater proportion of the population than any other care level.

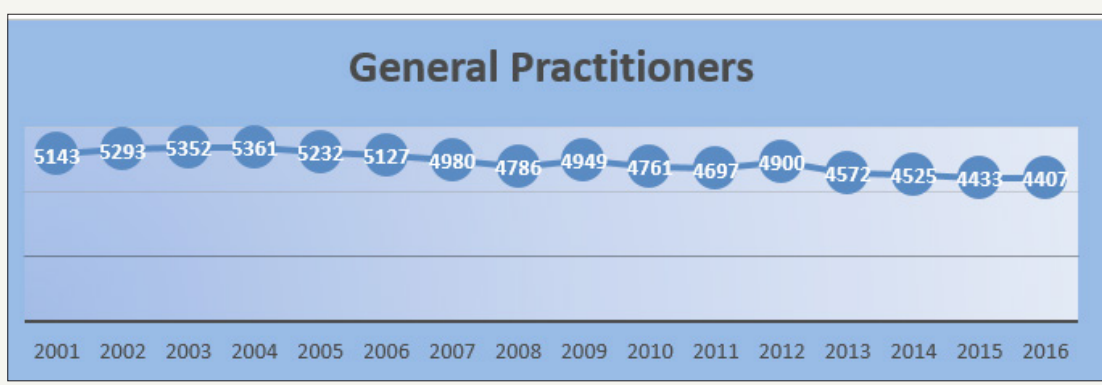

Figure 1: Number of general practitioners in Bulgaria for 2001-2016 according national institute of statistics.

At the end of 2017 the availability of doctors in Bulgaria was at about 1 doctor per 234 population, while the number of general practitioners was 1 per 1556 [1] with tends to decrease. There is a tendency towards pronounced disproportion in availability of doctors between different areas of the country. In the small towns and in the mountainous regions, availability of physicians decreases to 1 doctor per 367 population and the number of the general practitioners is 1 per 2106 [1]. Increases the age of working physicians in the country, about $50 \%$ of them are aged from 46 to 60 years and 20\% are over 60years. According National Association of General Practitioners in Bulgaria $-65 \%$ of them were over 50years for 2016. Given all these trends, the problem that occurs is -will 
there be enough GPs in the country, especially in some regions after a period of 5-10years.

Some studies reported that physicians who are dissatisfied with their work were most likely to leave the practice [2-5]. The reduced job satisfaction of the physicians and reduced number of the working doctors affect the quality of the health care services and the patient's satisfaction [2-7]. The aim of the study was to evaluate the professional satisfaction of GPs in Bulgaria and some of the factors that influence this satisfaction.

\section{Materials and Methods}

This cross-sectional study was conducted during JanuaryJune 2017 using a self-administered questionnaire. The data were collected from 136 GPs working in 136 primary care practices (practice principals) from different regions of the country. Out of 150 questionnaires that were distributed, 136 were received, at a response rate of $91 \%$. The participants were informed about the study objectives and that data collected would be used only for the stated research purposes. All responses were anonymous.

The questionnaire contained two parts:

A. Socio-demographic characteristics of the surveyed persons.

B. Job satisfaction questions.

Job satisfaction was measured with the 10-item Warr-CookWall satisfaction questionnaire with a 7-point Likert scale ranging from 1/extreme dissatisfaction/ to 7/extreme satisfaction/ [2,3,811]. Data are processed with software of Stat graphics and Excel.

\section{Results}

Participants in the survey were 136 GPs worked in 110 solo practices and 26 group practices from different regions of the country, 56 of them are male and 80-female. Most of our participants worked in urban regions $-53 \%$. The average number of staff employed by the surveyed practices is $2.98 \pm 0.52$ /SD3.08/. The socio-demographic characteristics of the participants are shown in Table 1.

Table 1: Characteristic of the participants.

\begin{tabular}{|c|c|c|}
\hline Characteristic & \multirow{2}{*}{ Number } & \multirow{2}{*}{ Percent (\%) } \\
\cline { 1 - 2 } Sex & 56 & 41 \\
\hline Male & 80 & 59 \\
\hline Mode of practice & \multicolumn{2}{|}{} \\
\hline Single handed & 110 & $81 \%$ \\
\hline Group practice & 26 & $19 \%$ \\
\hline Location of Main Practice Setting & \multicolumn{2}{|c|}{} \\
\hline rural & 28 & $21 \%$ \\
\hline small town & 26 & $26 \%$ \\
\hline urban & 53 & $53 \%$ \\
\hline
\end{tabular}

\begin{tabular}{|c|c|c|}
\hline Length of Experience & \multicolumn{2}{|}{} \\
\hline from 0 to 5 years & 12 & $9 \%$ \\
\hline from 6 to 15 years & 26 & $19 \%$ \\
\hline over 15 years & 98 & $72 \%$ \\
\hline Generally, & 136 & $100 \%$ \\
\hline Average age & \multicolumn{2}{|c|}{$48.62 \pm 1.48$} \\
\hline Number of team members & \multicolumn{2}{|c|}{$2.98 \pm 0.52$} \\
\hline
\end{tabular}

Table 2: Different items of job satisfaction of general practitioners in Bulgaria.

\begin{tabular}{|c|c|c|}
\hline WCW Items & Mean & SD \\
\hline Amount of variety in job & 5.41 & 1.67 \\
\hline Amount of responsibility & 6.26 & 1.21 \\
\hline Opportunity to use abilities & 5.73 & 1.37 \\
\hline Freedom of working method & 5.21 & 1.61 \\
\hline Physical working condition & 4.84 & 1.71 \\
\hline Hours of work & 4.75 & 2.07 \\
\hline Income & 4.31 & 1.62 \\
\hline Recognition for work & 4.18 & 0.31 \\
\hline Colleagues and fellow workers & 5.61 & 1.42 \\
\hline Overall job satisfaction & 5.07 & 1.34 \\
\hline
\end{tabular}

The participants generally report a high weekly workload with an average of $46.57 \pm 2.39$ hours /SD14,14/, which varies over a very wide range: from 10 to 70 hours. This evaluation was not affecting the location of the practice-urban or rural $/ p=0.15$; $r=0.12 /$, as well as the number of staff employed by the practice / $\mathrm{p}=0.96 ; \mathrm{r}=-0.04 /$. The satisfaction of physicians from their work in the general practice was evaluated by each of the 10 items on the standardized Warr-Cook-Wall /WCW/ job satisfaction scale. The overall job satisfaction was relatively good $/$ mean $=5.07 /$. Table 2 shows job satisfaction of the participants for each of the ten items of this scale.

The participants reported a high level of satisfaction with the "amount of responsibility" /mean=6.26/, the "opportunity to use abilities" /mean=5.73/, "relationships with colleagues and fellow workers" $/$ mean=5,61/ but low satisfaction with the "recognition for work" $/$ mean=4.18/, "income" /mean=4.31/, "hours of work" / mean $=4.75 /$ and the "physical working condition" $/$ mean $=4.84 /$.

\section{Discussion}

Like our study reported that the doctors in other countries of the European Region point out that the "hours of work" is the most unsatisfactory followed by their income. General practitioners from other regions of the world point out that their income is most unsatisfactory, and then "hours of work" or other factors. According to most authors GPs reported a high level of satisfaction with "freedom of working method" and relations with colleagues [2,3,913]. In similar studies, the recognition received by GPs is higher -it is usually found on the average rating, and only the Bulgarian 
doctors in primary health care have put such a low rating on this indicator [2,3,9-13].

There is no dependence between the doctors' satisfaction with the indicators and the location of their practice -urban or rural There was also no statistically significant difference between the male and female assessment of the surveyed indicators. The results showed that physician-patient relationships are one of the most important factors that has impact on the doctor's satisfaction. Our study showed that the participants have a satisfactory perception regarding their overall job satisfaction. There were significant associations between overall satisfaction and different items of job satisfaction.

\section{Conclusion}

The physician job satisfaction is an important condition of the quality of health care. The survey shows lower evaluation for identical indicators of Bulgarian GPs compared to their colleagues in the European countries. The indicators of the job satisfaction, which have the greatest impact on the low satisfaction of the General Practitioners in Bulgaria, have been considered. The study shows a very high weekly workload for some of the surveyed doctors. The main problems with the job satisfaction of the General practitioners in Bulgaria are the low pay, the long working day, the physical working conditions and above all -the recognition that they receive as doctors from the first level of the healthcare system of the country. The change of these indicators would greatly improve the satisfaction of the GP's work in Bulgaria.

\section{Acknowledgment}

The authors would like to thank the participating general practitioners for their cooperation with our study.

\section{References}

1. National Statistical Institute of Bulgaria. Bulgaria.
2. Buciuniene I, Blazeviciene A, Bliudziute E (2005) Health care reform and job satisfaction of primary health care physicians in Lithuania. BMC Fam Pract 6(1): 10.

3. Goetz K, Campbell S, Broge B, Brodowski M, Steinhaeuser J, et al. (2013) Job satisfaction of practice assistants in general practice in Germany: an observational study. Family Practice 30(4): 411-417.

4. Linzer M, Baier ML, Williams ES, Bobula JA, Brown RL, et al. (2009) Working conditions in primary care: physician reactions and care quality. Ann Int Med 151(1): 28-36.

5. Wallace JE, Lemaire JB, Ghali WA (2009) Physician wellness: a missing quality indicator. Lancet 374(9702): 1714-1721.

6. Szecsenyi J, Goetz K, Campbell S, Broge B, Reuschenbach B, et al. (2011) Is the job satisfaction of primary care team members associated with patient satisfaction? BMJ Qual Saf 20(6): 508-514.

7. Dowd BE, Kralewski JE, Kaissu AA, Irrgang SJ (2009) Is patient satisfaction influenced by the intensity of medical resource use by their physicians? Am J Manag Care 15(5): 16-21.

8. Engels Y, Dautzenberg M, Campbell S (2006) Testing a European set of indicators for the evaluation of the management of primary care practices. Fam Pract 23(1): 137-147.

9. Van Ham I, Verhoeven AAH, Groenier KH, Groothoff JW, De Haan J (2006) Job satisfaction among general practitioners: a systematic literature review. Eur J Gen Pract 12(4): 174-180.

10. Goetz K, Campbell S, Steinhaeuser J, Joachim S, Sara W, et al. (2011) Evaluation of job satisfaction of practice staff and general practitioners: an exploratory study. BMC Fam Pract 12: 137.

11. Goetz K, Marx M, Marx I (2015) Working atmosphere and job satisfaction of health care staff in kenya: an exploratory study. BioMed Research International p. 7.

12. Heritage B, Pollock C, Roberts L (2015) Confirmatory factor analysis of warr, cook and wall's (1979) job satisfaction scale. Australian Psychologist 50(2): 122-129.

13. Al Eisa I, Al Mutar M, Al Abduljalil H (2005) Job satisfaction of primary health care physicians at capital health region, kuwait. Middle East Journal of Family Medicine 3(3): 1-5.
Creative Commons Attribution 4.0

International License

For possible submissions Click Here

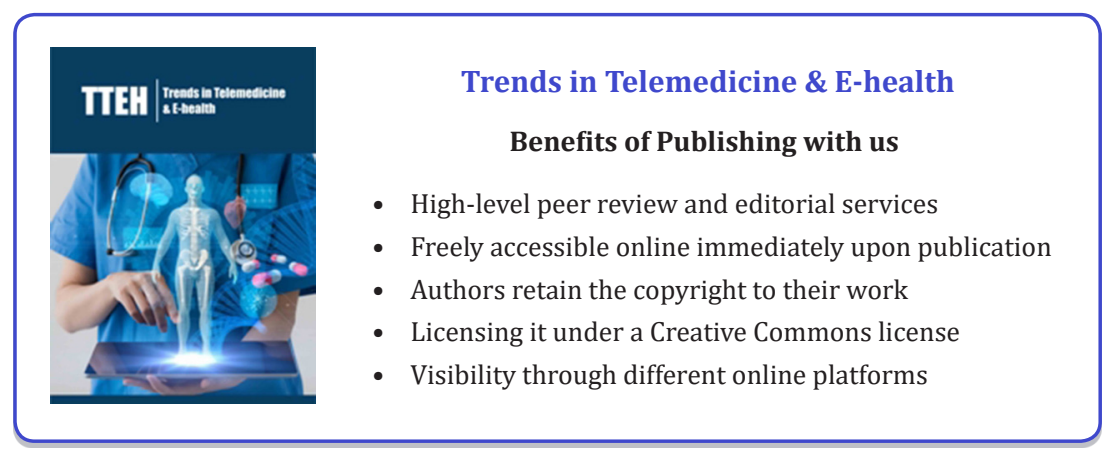

